\title{
Overexpression of reactive oxygen species modulator 1 is associated with advanced grades of bladder cancer
}

\author{
Hadi Ghasemi ${ }^{1}$ - Mohammad Amin Amini ${ }^{1}$ - Atefeh Pegah ${ }^{1}$ - Ebrahim Azizi ${ }^{2} \cdot$ Heidar Tayebinia ${ }^{1}$. \\ Shima Khanverdilou' ${ }^{1}$. Seyed Habibollah Mousavibahar ${ }^{4}$. Aida Alizamir ${ }^{3}$
}

Received: 11 May 2020 / Accepted: 1 August 2020 / Published online: 8 August 2020

(c) Springer Nature B.V. 2020

\begin{abstract}
Reactive Oxygen Species Modulator 1 (ROMO1) plays a pivotal role in the regulation of mitochondrial structure integrity, and the production of reactive oxygen species (ROS). Increased ROMO1 expression was reported in various cancer cell lines; however, the possible association between ROMO1 expression and bladder cancer was not well studied. The present study aimed to investigate the rate of ROMO1 expression and the correlation of oxidative stress with the development of bladder cancer. In this study, a total of 35 cancerous and healthy adjacent tissues were examined using quantitative real-time polymerase chain reaction (qRT-PCR) to analyze the gene expression of ROMO1. Also, we evaluated the serum level of ROMO1 and Total Antioxidant Capacity (TAC), as well as Total Oxidant Status (TOS) in patients with bladder cancer along with age- and sex-matched healthy individuals. The ROMO1 gene was significantly higher in cancerous tissues than that of adjacent healthy tissues. Also, the serum levels of ROMO1, TAC, TOS, and Oxidative Stress Index (OSI) were increased in patients with bladder cancer compared with healthy subjects. It can be concluded that the overexpression of the ROMO1 gene is associated with advanced grades of bladder cancer as well as an increase in oxidative stress conditions. Our findings also suggest that the serum level of ROMO1 might be a promising tumor marker for bladder cancer.
\end{abstract}

Keywords ROMO1 $\cdot$ Bladder cancer $\cdot$ Gene expression $\cdot$ Tumor marker $\cdot$ Oxidative stress

\section{Introduction}

Bladder Cancer is a common name for urothelial cell carcinoma (the lining of the urinary tract from the pelvis to the urethra), and it is the most common malignancies of the urinary tract $[1,2]$. In 2015 , the prevalence of this cancer

Hadi Ghasemi and Mohammad Amin Amini contributed equally to this manuscript.

Aida Alizamir

Aidaalizamir@yahoo.com

1 Department of Clinical Biochemistry, Hamadan University of Medical Sciences, Hamadan, Iran

2 Department of Nephrology and Urology Research Center, Hamadan University of Medical Sciences, Beheshti Hospital, Hamadan, Iran

3 Department of Pathology, School of Medicine, Hamadan University of Medical Sciences, Hamadan, Iran

4 Department of Urology, School of Medicine, Hamadan University of Medical Sciences, Hamadan, Iran in the United States was reported to be 74,000 , of which approximately 16,000 were fatal [3]. According to epidemiological studies, more than $90 \%$ of bladder cancer cases diagnosed in North America and Europe are categorized as urothelial carcinoma. Bladder cancer is mainly classified into non-muscle-invasive bladder cancer (NMIBC) and muscle-invasive bladder cancer (MIBC) [4]. NMIBC, as a highly prevalent bladder cancer with a $50-70 \%$ recurrence rate, accounts for $75 \%$ of all bladder cancer cases. The remaining cases diagnosed with MIBC have a higher rate of mortality [5]. According to the grading system of the bladder cancer, $70 \%$ of bladder cancer cases are diagnosed as low-grade, non-invasive with superficial papillary growing. High-grade bladder cancer is characterized by the progression of invasive tumors and diagnosed in $30 \%$ of patients with bladder cancer [6].

Oxidative stress, defined as a disturbance in the balance between reactive oxygen species (ROS) production and antioxidant agents, can alter the redox homeostasis into the cells and leads to oxidative damage to the DNA and may contribute to the tumor progression and development [7, 8]. Mitochondria, 
as the powerhouse of the cells, is considered the major source of ROS production in various cells [9].

One of the most significant proteins involved in the production and regulation of Reactive Oxygen Species (ROS) is ROS Modulator 1 (ROMO1). ROMOI is a mitochondrial protein that was first identified in cancerous tissues in 2006, as a group of researchers found that some cancerous tissues develop drug resistance during chemotherapy [10-12]. It was reported that ROMO1 was localized in the mitochondria and play a pivotal role in maintaining the redox signaling in normal and cancer cells [13]. ROMO1, a ROS modulator protein, was characterized in various cancer cells, and also implicated in the invasion and development of cancer cells $[10,14]$. ROS can lead to proliferation and metastasis through different pathways, including $N F-\kappa B, E R K, M A P K, p 53$, and $P I 3-K$ in various types of cancer $[10,15,16]$. Also, in-vitro studies performed on ROMO1 demonstrated the carcinogenicity of this protein in a few cases [10,14]. In previous studies conducted on hepatic carcinoma, it has been suggested that increased gene expression of ROMO1 in cancerous tissues may be responsible for invasion and growth of tumor cells, which could be considered a useful biomarker for the diagnosis and treatment of different neoplasms [10, 14]. Increased ROMOI gene expression in tumor cells cause excessive ROS production and followed damage to mitochondrial DNA and nucleus [14]. Besides, it has been reported that $R O M O 1$-induced ROS overproduction is associated with the recurrence of various cancer types [14, 17]. However, it is worth noting that ROMOl-induced ROS production is also essential for normal cells [18]. Not only is $R O M O-1$ requisite for physiological functions of mitochondria to generate ROS, but it also plays a critical role in the maintenance of the morphology of mitochondria and the integrity of their inner membrane structures [14, 19]. In addition to the effect of $R O M O 1$ on free radical production, $R O M O 1$ can also affect the cell cycle process, as decreased expression of this protein causes cell cycle arrest at the $G 2 / M$ stage [19]. Aberrant $R O M O 1$ expression can enhance the generation ROS in normal cells which can transform these cells into cancer cells [20]. However, ROMOI expression and then induced oxidative stress have not been studied in bladder cancer. In the present study, we demonstrated that the ROMOI gene expression and its serum level, as well as induced oxidative stress, are critical for bladder cancer progression and positively correlated with bladder cancer higher grade.

\section{Materials and methods}

\section{Patients and study design}

The study protocol was reviewed and approved by the Ethics Committee of Hamadan University of Medical Sciences. A total of 35 bladder cancer patients and 35 healthy controls were consecutively recruited between April 2019 and January 2020 from Shahid Beheshti Hospital of Hamadan, Iran. Written informed consent was obtained from all patients and control participants. Bladder cancer tissue specimens were obtained from patients who underwent transurethral resection of bladder cancer. The diagnosis of cancerous tissues and their grading system was performed by a trained pathologist based on standard protocols. Bladder cancerous and healthy adjacent tissues were surgically obtained from 35 patients and divided into two parts; one part was frozen in liquid nitrogen and specified for RNA extraction, cDNA synthesis, and gene expression analysis, while the other part was fixed in $10 \%$ formalin for pathological examinations. Blood samples were also collected from patients with bladder cancer, as well as age and sex-matched healthy individuals. Sera were isolated from the whole blood specimens and stored at $-70{ }^{\circ} \mathrm{C}$ for the biochemical assay. Demographic characteristics, such as age, sex, site of primary neoplasm, date of diagnosis, family history of cancer, and history of the other diseases were recorded. Subjects with acute or chronic disorders, other malignancies, and a history of chemotherapy and radiotherapy were excluded from the study.

\section{Transurethral resection (TUR) of bladder tumor}

Following the cystoscopy procedure, patients with cell abnormalities were selected to undergo Transurethral resection (TUR) of bladder tumors. In this procedure, cancerous tissues are removed and histopathologically graded by a trained pathologist.

\section{Pathological examination}

Bladder cancer and normal-appearing adjacent tissue samples were immediately fixed using formalin $10 \%$ and then embedded in paraffin. The prepared sections were examined with hematoxylin and eosin staining and reviewed by a pathologist. For this propose, tissue sections at a thickness of $5 \mu \mathrm{m}$ were first stained using with Harris' hematoxylin solution for $10 \mathrm{~min}$. Samples were washed in tap water until the water was colorless, then tissue specimens were differentiated using acid ethanol $(1 \mathrm{ml}$ concentrated $\mathrm{HCl}+400 \mathrm{ml} \mathrm{70 \%}$ ethanol in water). Next, after rinsing in tap water for $2 \mathrm{~min}$, samples were stained with the eosin $\mathrm{Y}$ ethanol solution. Finally, the stained sections were cleared using xylene and then mounted on slides and coverslipped. H\&E stained tissue sections were examined under light microscopy, and appropriate samples were selected for the analysis. Samples stained with H\&E are shown in Fig. 1. 


\section{RNA extraction and real-time PCR}

Total RNA was extracted using the RNX-Plus solution (Cinnagen, Tehran, Iran) according to the manufacturer's protocols. The extracted RNA was quantitatively and qualitatively evaluated by nanodrop (Thermo Fisher Scientific Inc., USA) and $1 \%$ agarose gel, respectively. Complementary DNA (cDNA) was then synthesized with Revert Aid TM First Strand cDNA Synthesis Kit (Fermentas). Real-time PCR was performed by SYBR Green master mix (Amplicon, Denmark) in the Light Cycler 96 instruments (Roche Life Science Deutschland GmbH, Sandhofer, Germany). Specific Primer sets were designed in accordance with the GenBank database (https://www.ncbi. nlm.nih.gov) and synthesized by Takapou Zist Company. The primer sequences were as follows: ROMOI (Forward:
5'-CTGTCTCAGGATCGGAATGCG-3'; Reverse: 5'- CAT CGGATGCCCATCCCAATG-3') and beta-actin (Forward: 5'-ACAGAGCCTCGCCTTTGC - 3'; Reverse: 5'-ATC ACGCCCTGGTGCCT $-3^{\prime}$ ). The difference in the relative gene expression in comparison with the reference gene was estimated using the $2^{\wedge}-\Delta \Delta \mathrm{CT}$ formula [21].

\section{Measurement of serum total antioxidant capacity (TAC)}

For the determination of Total Antioxidant Capacity (TAC), ferric reducing antioxidant power (FRAP) was measured. In this method, the reduction of the ferric (Fe III) tripyridyltriazine (TPTZ) complex to Fe II can be determined at low $\mathrm{pH}$ by measuring the optical absorption at a wavelength of $593 \mathrm{~nm}[22]$.
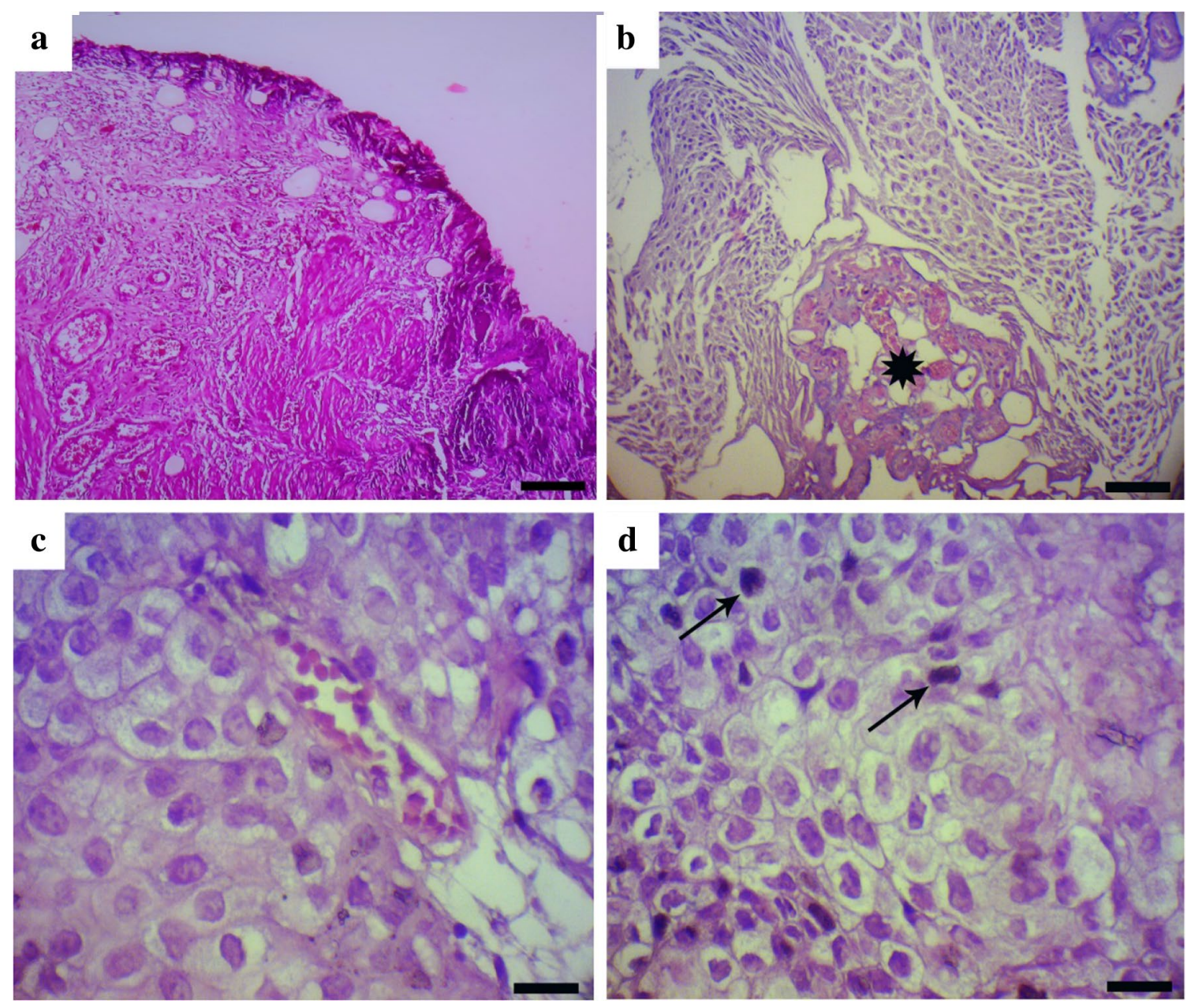

Fig. 1 Hematoxylin and eosin staining of bladder carcinoma. a normal appearing bladder adjacent tissue (H\&E staining; $B a r=100 \mu \mathrm{m})$; b fibrovascular core in the center of projection (star) (H\&E staining; Bar $=60 \mu \mathrm{m})$; c tumor cells with slight size variation, mild loss of

cellular polarity and mildly abnormal chromatin (H\&E staining; Bar $=25 \mu \mathrm{m}$ ); $\mathbf{d}$ A few mitosis near to the basal lamina (arrows) (H\&E staining; Bar $=25 \mu \mathrm{m}$ ) 


\section{Measurement of serum total oxidant status (TOS)}

Total Oxidant Status (TOS) of the serum samples was assessed by oxidation of ferrous iron to ferric ion in moderate acidic $\mathrm{pH}$ values in samples utilizing xylenol orange. The optical intensity of specimens was measured at a wavelength of $560 \mathrm{~nm}$ [23].

\section{Measurement of ROMO-1 contents in the serum of patients and healthy subjects}

The serum levels of ROMO1 was analyzed by the commercially available ELISA kit (Bioassay Technology Laboratory, E2143Hu) in sera of patients and healthy individuals according to the manufacturer's recommendations. All serum specimens were tested blinded.

\section{Data analysis}

The statistical analysis was performed by SPSS software version 16 (SPSS Inc., Chicago, IL). To compare the relative expression ratios of this gene between the two study groups, the normal distribution of data was evaluated by the Kolmogorov-Smirnov test, and the proportions of the results of parametric and non-parametric variables were assessed using Mann-Whitney and Student T-tests. In this study, the p-value of less than 0.05 was statistically considered significant. The Spearman and Pearson correlation coefficients were used to analysis of the relationship between variables in terms of parametric and non-parametric proportions.

\section{Results}

\section{Demographic characteristics of participants}

A total of 35 cancerous, along with 35 adjacent healthy tissues, were taken from patients diagnosed with bladder cancer (Table 1). Fifteen patients $(42.85 \%)$ were under 67 years old, while the rest $(57.14 \%)$ were over 67 years old. Notably, histopathological analyses of the obtained samples were carried out according to the WHO urothelial bladder carcinoma grading system [24]. Specimens were graded as Grade I (13/35), Grade II (11/35), and Grade III (6/35). Seven patients (20\%) were diagnosed with multifocal bladder cancer, while 28 patients $(80 \%)$ had no signs of multifocal bladder cancer.

\section{ROM01 gene expression in cancerous and adjacent healthy tissues}

In this study, our findings demonstrated that the expression of ROMO1 was significantly correlated with tumor size $(\mathrm{r}=-0.339, \mathrm{p}=0.046)$ and histopathological grading $(r=0.772, p<0.001)$ in bladder cancer patients (Fig. 2b). The expression level of the ROMO1 gene was evaluated in cancerous and healthy adjacent tissues and found that its expression was markedly higher in bladder cancerous tissues compared with adjacent healthy tissues $(\mathrm{P}<0.05$, Fig. 2a). Also, we observed that the expression level of the ROMO1 gene was positively associated with its serum concentrations $(\mathrm{p}<0.001, \mathrm{r}=0.5816)$ (Fig. 3b).

\section{Serum levels of ROMO1 were positively correlated with ROM01 expression}

The serum levels of ROMO1 was increased significantly in patients with bladder cancer in comparison with healthy individuals $(\mathrm{P}<0.05$, Fig. 3a). A positive correlation was also detected between the serum level of ROMO1 and histopathological grading in patients with bladder cancer $(\mathrm{r}=0.567, \mathrm{p}>0.001)$ (Fig. 2c). Moreover, the Receiver Operating Characteristic (ROC) curve analysis was carried out to explore whether serum level of ROMO1 could be used as a potential marker for bladder tumors in 70 sample
Table 1 Clinicopathological parameters of bladder cancer patients $(\mathrm{n}=35)$

\begin{tabular}{|c|c|c|c|c|c|c|}
\hline Characteristic & Categorization & $\mathrm{N}(\%)$ & $\begin{array}{l}\text { F.C. of ROMO1 } \\
\text { Mean } \pm \text { SD }\end{array}$ & $P$ value & $\begin{array}{l}\text { Serum } \\
\text { ROMO1 } \\
\text { Mean } \pm \text { SD }\end{array}$ & $P$ value \\
\hline \multirow[t]{2}{*}{ Age, years } & $\leqq 67$ & $15(42.85)$ & $7.13 \pm 2.49$ & 0.412 & $2.57 \pm 0.76$ & 0.544 \\
\hline & $>67$ & $20(57.14)$ & $7.77 \pm 2.04$ & & $2.39 \pm 0.91$ & \\
\hline \multirow[t]{2}{*}{ Smoking } & Yes & $24(68.58)$ & $7.87 \pm 2.04$ & 0.139 & $2.56 \pm 0.93$ & 0.363 \\
\hline & No & $11(31.42)$ & $6.66 \pm 2.50$ & & $2.27 \pm 0.60$ & \\
\hline \multirow[t]{3}{*}{ Grade } & Grade I & $13(37.14)$ & $5.17 \pm 1.99$ & $<0.001$ & $2.02 \pm 0.70$ & $<0.001$ \\
\hline & Grade II & $16(45.71)$ & $8.33 \pm 0.66$ & & $2.42 \pm 0.74$ & \\
\hline & Grade III & $6(17.14)$ & $9.77 \pm 1.51$ & & $3.50 \pm 0.49$ & \\
\hline \multirow[t]{2}{*}{ Tumor size, $\mathrm{cm}$} & $\leqq 2.0$ & $21(60.0)$ & $6.88 \pm 2.24$ & 0.046 & $2.34 \pm 0.73$ & 0.273 \\
\hline & $>2.0$ & $14(40.0)$ & $8.41 \pm 1.95$ & & $2.66 \pm 0.98$ & \\
\hline \multirow[t]{2}{*}{ Multifocality } & Multifocality & $7(20.0)$ & $9.26 \pm 1.73$ & 0.038 & $2.69 \pm 0.92$ & 0.193 \\
\hline & No multifocality & $28(80.0)$ & $6.03 \pm 1.94$ & & $2.24 \pm 0.83$ & \\
\hline
\end{tabular}


a

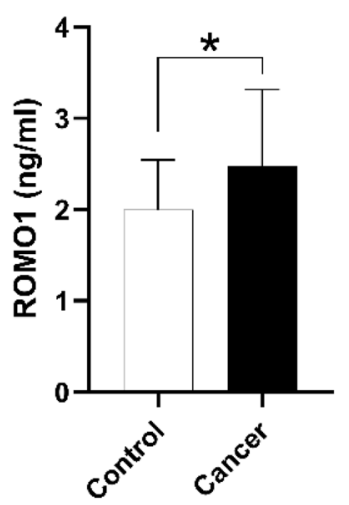

b

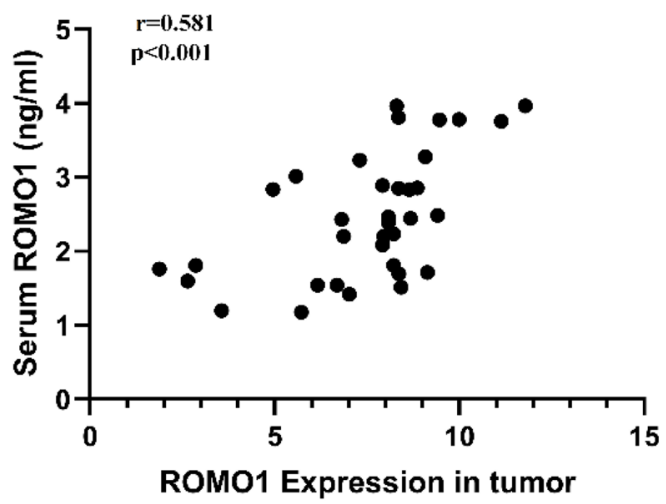

c

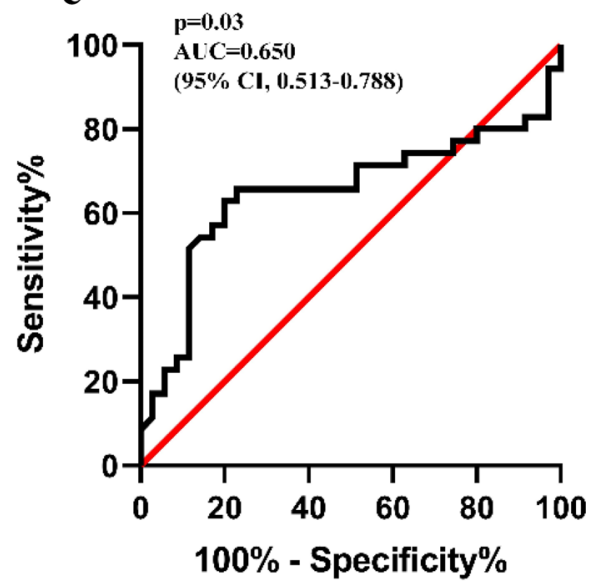

Fig. 2 Serum levels of ROMO1 were significantly associated with ROMO1 gene expression. a Serum levels of ROMO1 were higher in bladder cancer when compared to control group. b there was a positive correlation between Serum levels of ROMO1 and its gene expression. c The ROC curve analysis for ROMO1 serum levels in patients with bladder cancer and control subjects. ${ }^{*} \mathrm{p}<0.05$ in all comparisons
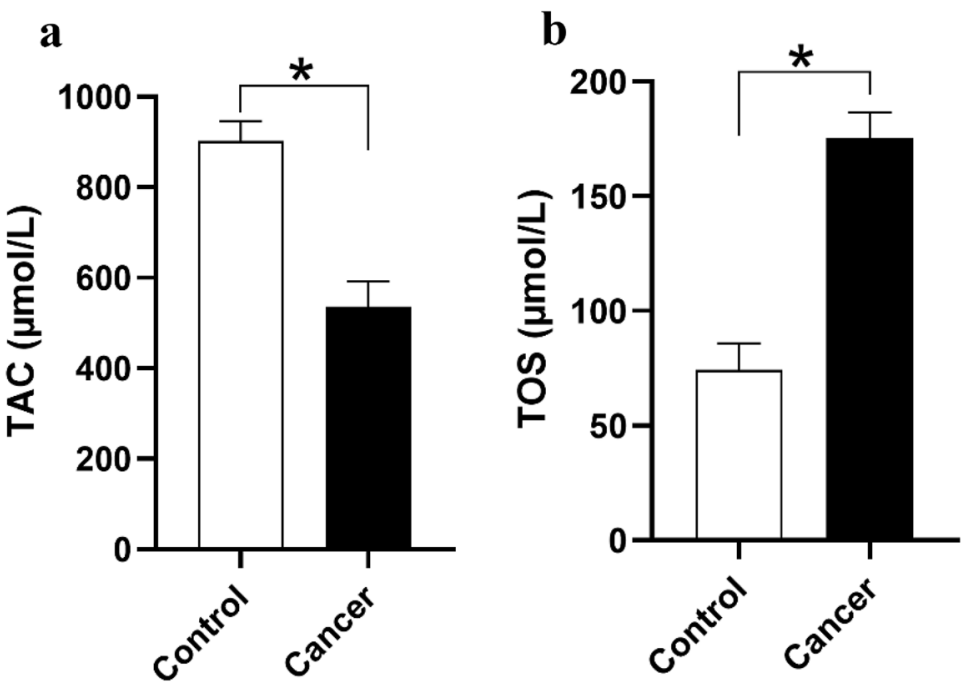

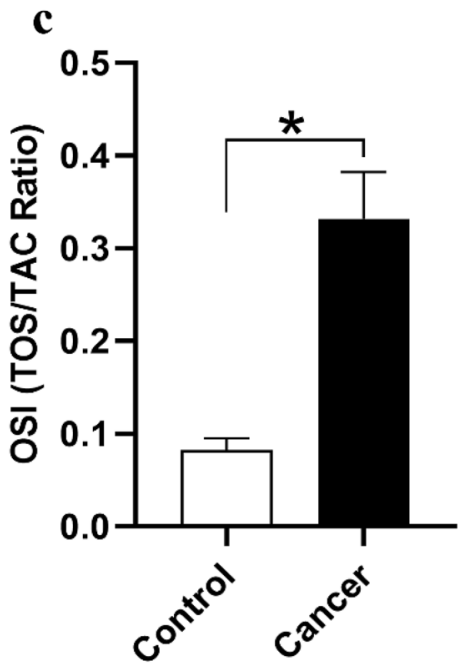

Fig. 3 a Serum Level of TAC and TOS and OSI ratio bladder cancer patients and control group. a Serum Level of TAC was lower in bladder cancer patients. b Serum Level of TOS was higher in blad- der cancer patients. c The OSI ratio was higher in bladder cancer as compared to control group. $* \mathrm{P}<0.05$ is considered significant for all comparisons sets. The ROC curve analysis showed that an area under the curve (AUC) [0.650 (95\% CI 0.513-0.788)] suggests that ROMO1 is capable of being applied as a tumor marker for bladder cancer (Fig. 3c).

\section{Measurement of oxidative stress parameters}

\section{Level of TAC in serum patients and healthy individuals}

Total Antioxidant Capacity in serum specimens of patients with bladder cancer $(n=35)$ and healthy individuals $(n=35)$ was analyzed, and it was found that the parameter was markedly lower in serum samples of patients with bladder cancer in comparison with healthy subjects $(\mathrm{P}<0.05$ Fig. 4).

\section{Level of TOS in serum patients and healthy subjects}

The results indicated that the level of TOS in patients with bladder cancer was significantly higher when compared with healthy subjects $(\mathrm{P}<0.05$, Fig. 4). 


\section{OSI parameter}

Oxidative Stress Index (OSI) is defined by the ratio of TOS to TAC (Fig. 4). This index was significantly higher in [patients with bladder cancer than that of healthy individuals $(\mathrm{P}<0.05)$.

\section{Discussion}

Oxidative stress can cause tumor growth, cell invasion, metastasis, and angiogenesis in cancer cells [18, 25]. Generally, increased levels of ROS can lead to cellular damage, inflammation, and DNA mutation, which may eventually result in the development of cancer [18, 25].

ROMOI is one of the most critical mitochondrial membrane proteins that can contribute to the regulation and production of ROS, as well as the protection of the mitochondrial membrane and its structure [26]. The overexpression of ROMO1 has been shown in different disorders, especially cancer. The excess levels of ROMOI can leads to an injury to the mitochondria structure and promotes oxidative stress in cells. However, ROMO1 expression and possibly induced oxidative stress as well as its relationship with bladder cancer awaits investigation to clarify.

According to our findings, significant overexpression of the ROMO1 gene was observed in bladder cancer tissues as compared with adjacent healthy tissues. Besides, in parallel with the increase in the expression of this gene, the serum levels of ROMOI were significantly elevated in patients with bladder cancer compared with healthy subjects. We also found a positive correlation between ROMO1 expression and its serum concentrations.

Recently, Amini and colleagues have found that increased expression of $R O M O 1$ plays an essential role in the growth and development of gastric cancer [27]. Several lines of evidence demonstrated that increased expression of $R O M O 1$ and oxidative stress are positively correlated to different pathologic conditions. For instance, Kim et al. have reported the overexpression of ROMO1 in colorectal cancer tissues. They also suggested that this protein might be considered a good candidate as a diagnostic biomarker [28]. The study on ROMO1 gene polymorphism showed that single nucleotide polymorphisms within the ROMOI gene along with other factors, such as H. Pylori infection and smoking, could be considered as risk factors for the development of gastric cancer [29]. This study highlights the positive correlation between ROMO1 gene and protein expression and bladder cancer histological grading, which was in accordance with previously reported data that $R O M O 1$ was associated with higher grade and poor prognosis in other cancer types [30].

Accordingly, we hypothesized that $\mathrm{ROMOI}$ overexpression facilitates ROS production and induces oxidative stress. To test this hypothesis, we have investigated the oxidative stress markers in the serum. Increased oxidative stress indices (TOS and OSI), along with decreased oxidative stress index (TAC), were observed in serum samples of patients with bladder cancer. ROS are involved in various physiological processes in normal cells; however, a certain level of ROS is required for the function of normal cells [18]. Accumulation of ROS can affect cellular physiology, such

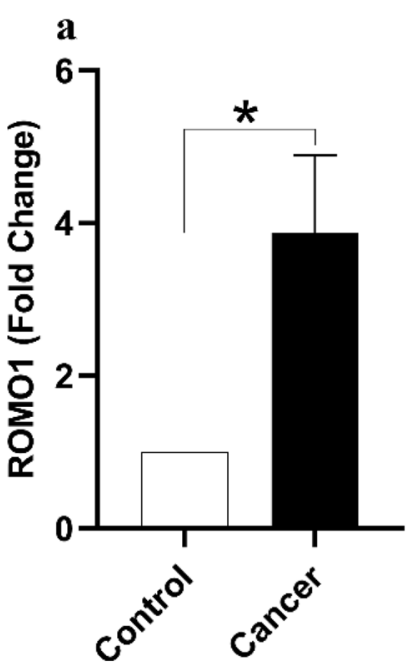

b

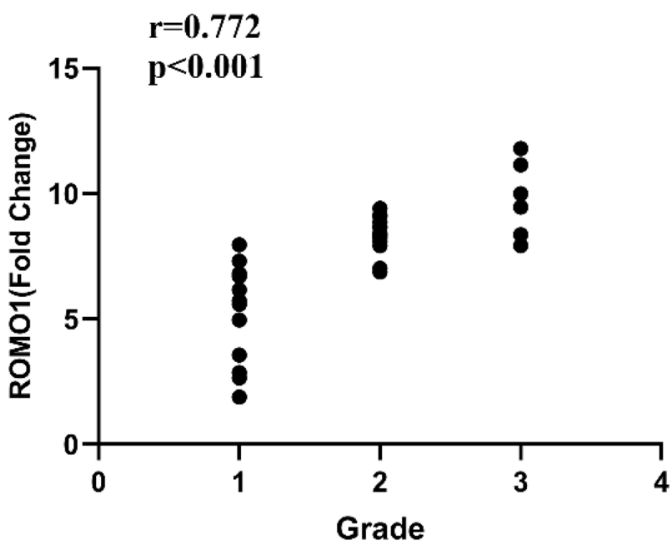

c

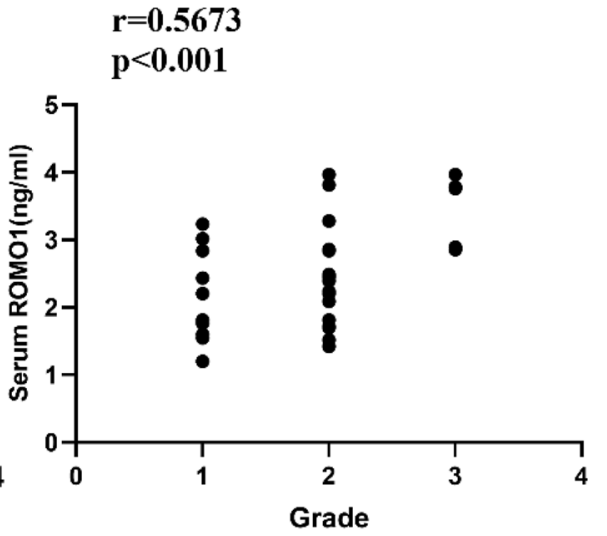

Fig. 4 ROMO1 gene expression and serum protein level were positively associated with histopathological grading in bladder cancer. a ROMO1 gene expression was higher in bladder cancer. b ROMO1 gene expression was positively associated with histopathological grading in bladder cancer. c Serum level of ROMO1 was positively associated with histopathological grading in bladder cancer. *p < 0.05 in all comparisons 
as the aberrant activation of different metabolic pathways. It has been reported that induced oxidative stress can make cause detrimental effects on normal cell function and drive these cells to differentiate into cancer cells [18]. As recently observed, free radical agents are increased parallel with the overexpression of ROMOI, which can impair the mitochondrial function. Therefore, in this research, we showed that parallel with an increase in the expression of ROMOI, the concentration of free radicals was elevated and led to the development of cancer. In line with present study results, a study performed on patients with esophageal cancer showed an increased level of TOS and OSI, as well as the decreased levels of TAC in patients [31, 32]. The research suggested that TOS and OSI can be used as biochemical indices for the diagnosis of esophageal cancer. As mentioned earlier, $R O M O 1$, as a ROS modulator and regulator of the mitochondria function, has been detected in different types of cancers, and contribute to the progression and invasion of cancer cells, thereby various signaling and metabolic pathways. For example, ROS can activate both extracellular signal-regulated kinases $(E R K)$ and $N F-k B$ pathways $[15,33,34]$. It has also been reported that oxidative stress strongly reduces the response of bladder cancer cells to Bacillus Calmette-Guérin (BCG) immunotherapy [35]. BCG administration is the most functional intravesical treatment used for the treatment of bladder cancer. Most importantly, BCG immunotherapy may provide prophylaxis against COVID-19 in bladder cancer patients [36]. On the other hand, it has been reported that the overexpression of ROMO1 can cause damages to the mitochondrial structure and an increment in oxidative stress [18, 37, 38]; Accordingly, in patients with bladder cancer, ROMO1 overexpression may interfere with the prophylactic role of BCG immunotherapy against COVID19. Additionally, it has been suggested that ROMOI could also influence the cell cycle at the $G 2 / M$ stage; therefore, a decrease in the expression of $R O M O 1$ results in cell cycle arrest at the $G 2 / M$ phase [39]. As expected, our findings demonstrated that the expression of ROMOl was higher in comparison with healthy subjects that could stem from an oxidative stress condition, as the overexpression of $\mathrm{ROMOI}$ consequently leads to the disruption of mitochondrial membrane and its structure [37], as well as Our findings indicated higher oxidative stress parameters in patients with bladder cancer. Collectively, it can be suggested that the overexpression of the ROMOI gene is linked with the development of bladder cancer.

In the present study, we also found that the overexpression of the ROMOl gene and protein expression had a significant correlation with the advanced grades of bladder cancer, and increased expression of this gene may promote cancer cell invasion, growth, and tumor tissue proliferation. It can be concluded that ROMOI plays a vital role in the development of bladder cancer, especially in advanced grades, and overexpression of this gene can be considered a prognostic marker for the screen of patients with bladder cancer. For this purpose, we have investigated the ROC curve analysis of serum ROMOI level. Interestingly, ROC curve analysis suggested that $R O M O 1$ could be considered as a potential tumor marker for bladder cancer. ROMOI has shown to be a potential biomarker in cancer and anticipate unfavorable prognosis in cancer [27]. Finally, it can be concluded that this important mitochondrial protein can predispose individuals to develop bladder cancer, thereby increasing the level of free radical agents. Thus, the analysis of this gene/protein could be a useful biomarker for screening patients with bladder cancer.

\section{Conclusions}

We demonstrated that the overexpression of the ROMOI gene is associated with advanced grades of bladder cancer as well as an increase in oxidative stress conditions. These phenomena could be mediated via different signaling pathways, and finally led to cancer cell proliferation. It seems that the analysis of ROMOI is to be a useful prognostic marker to predict the survival of patients with bladder cancer, along with their response to different therapeutic agents. Further research is warranted to unravel the precise role of this mitochondrial protein in the development of bladder cancer.

Acknowledgements We would like to appreciate the patients and healthy people who made this study possible.

Funding This work was funded by the Hamadan University of Medical Sciences under Grant No. 9804253259.

\section{Compliance with ethical standards}

Conflict of interest All the authors have declared that no conflict interest exists.

Ethical approval All procedures performed in studies involving human participants were in accordance with the ethical standards of the institutional and/or national research committee of Hamadan University of medical Sciences.

Informed consent Informed consent was obtained from all participant involved in the study.

\section{References}

1. Knollman H, Godwin JL, Jain R, Wong Y-N, Plimack ER, Geynisman DM (2015) Muscle-invasive urothelial bladder cancer: an 
update on systemic therapy. Ther Adv Urol 7(6):312-330. https ://doi.org/10.1177/1756287215607418

2. Schulz W (2005) Molecular biology of human cancers: an advanced student's textbook. Springer, New York, ISBN 978-1-4020-3186-1

3. Siegel RL, Miller KD, Jemal A (2015) Cancer statistics, 2015. CA Cancer J Clin 65(1):5-29. https://doi.org/10.3322/caac.21254

4. Soukup V, Čapoun O, Cohen D, Hernández V, Burger M, Compérat E, Gontero P, Lam T, Mostafid AH, Palou J, van Rhijn BWG, Rouprêt M, Shariat SF, Sylvester R, Yuan Y, Zigeuner R, Babjuk M (2020) Risk stratification tools and prognostic models in nonmuscle-invasive bladder cancer: a critical assessment from the European Association of Urology non-muscle-invasive bladder cancer guidelines panel. Eur Urol Focus 6(3):479-489. https:// doi.org/10.1016/j.euf.2018.11.005

5. Knowles MA, Hurst CD (2015) Molecular biology of bladder cancer: new insights into pathogenesis and clinical diversity. Nat Rev Cancer 15(1):25-41. https://doi.org/10.1038/nrc3817

6. Apollo A, Ortenzi V, Scatena C, Zavaglia K, Aretini P, Lessi F, Franceschi S, Tomei S, Sepich CA, Viacava P, Mazzanti CM, Naccarato AG (2019) Molecular characterization of low grade and high grade bladder cancer. PLoS ONE 14(1):e0210635. https ://doi.org/10.1371/journal.pone.0210635

7. Wu H, Gu Y-h, Wei L, Guo T-k, Zhao Y, Su G, Li J, Xie X-d (2015) Association of Romo1 gene genetic polymorphisms with risk of gastric cancer in northwestern Chinese population. Pathol Oncol Res 21(3):581-587. https://doi.org/10.1007/s1225 3-014-9858-7

8. Kim YS, Sull JW, Sung HJ (2012) Suppressing effect of resveratrol on the migration and invasion of human metastatic lung and cervical cancer cells. Mol Biol Rep 39(9):8709-8716. https://doi. org/10.1007/s11033-012-1728-3

9. Chen Q, Vazquez EJ, Moghaddas S, Hoppel CL, Lesnefsky EJ (2003) Production of reactive oxygen species by mitochondria central role of complex III. J Biol Chem 278(38):36027-36031. https://doi.org/10.1074/jbc.m304854200

10. Jo MJ, Kim HJ, Lee S-Y, Lee D-H, Oh SC (2017) Reactive oxygen species modulator 1 (Romo1) predicts unfavorable prognosis in colorectal cancer patients. AACR. https://doi.org/10.1371/journ al.pone. 0176834

11. Amini MA, Talebi SS, Karimi J (2019) Reactive Oxygen Species Modulator 1 (ROMO1), a new potential target for cancer diagnosis and treatment. Chonnam Med J 55(3):136-143. https://doi. org/10.4068/cmj.2019.55.3.136

12. Maiti AK (2013) Erratum to: Overcoming drug resistance through elevation of ROS in cancer. In: Molecular mechanisms of tumor cell resistance to chemotherapy. Springer, pp E1-E3. https://doi. org/10.1007/978-1-4614-7070-0_7

13. Lee SB, Kim HJ, Shin J, Kang ST, Kang S, Yoo YD (2011) BclXL prevents serum deprivation-induced oxidative stress mediated by Romo1. Oncol Rep 25(5):1337-1342. https://doi.org/10.3892/ or.2011.1210

14. Norton M, Ng AC-H, Baird S, Dumoulin A, Shutt T, Mah N, Andrade-Navarro MA, McBride HM, Screaton RA (2014) ROMO1 is an essential redox-dependent regulator of mitochondrial dynamics. Sci Signal 7(310):ra10-ra10. https://doi. org/10.1126/scisignal.2004374

15. Na AR, Chung YM, Lee SB, Park SH, Lee M-S, Do Yoo Y (2008) A critical role for Romo1-derived ROS in cell proliferation. Biochem Biophys Res Commun 369(2):672-678. https:// doi.org/10.1016/j.bbrc.2008.02.098

16. You BR, Park WH (2011) The enhancement of propyl gallateinduced HeLa cell death by MAPK inhibitors is accompanied by increasing ROS levels. Mol Biol Rep 38(4):2349-2358. https ://doi.org/10.1007/s11033-010-0368-8
17. Santiago-Arteche R, Muniz P, Cavia-Saiz M, Garcia-Giron C, Garcia-Gonzalez M, Llorente-Ayala B, Coma-del Corral M (2012) Cancer chemotherapy reduces plasma total polyphenols and total antioxidants capacity in colorectal cancer patients. Mol Biol Rep 39(10):9355-9360. https://doi.org/10.1007/s1103 3-012-1760-3

18. Lin S, Li Y, Zamyatnin AA Jr, Werner J, Bazhin AV (2018) Reactive oxygen species and colorectal cancer. J Cell Physiol 233(7):5119-5132. https://doi.org/10.1002/jcp.26356

19. Yu MO, Song N-H, Park K-J, Park D-H, Kim S-H, Chae Y-S, Chung Y-G, Chi S-G, Kang S-H (2015) Romo1 is associated with ROS production and cellular growth in human gliomas. J Neurooncol 121(1):73-81. https://doi.org/10.1007/s1106 0-014-1608-x

20. Nowell PC (1986) Mechanisms of tumor progression. Cancer Res 46(5):2203-2207

21. Livak KJ, Schmittgen TD (2001) Analysis of relative gene expression data using real-time quantitative PCR and the $2^{-\triangle \Delta C T}$ method. Methods 25(4):402-408. https://doi.org/10.1006/meth.2001.1262

22. Benzie IF, Strain JJ (1996) The ferric reducing ability of plasma (FRAP) as a measure of "antioxidant power": the FRAP assay. Anal Biochem 239(1):70-76

23. Erel O (2005) A new automated colorimetric method for measuring total oxidant status. Clin Biochem 38(12):1103-1111. https ://doi.org/10.1016/j.clinbiochem.2005.08.008

24. Moch H, Cubilla AL, Humphrey PA, Reuter VE, Ulbright TM (2016) The 2016 WHO classification of tumours of the urinary system and male genital organs - part A: renal, penile, and testicular tumours. Eur Urol 70(1):93-105. https://doi.org/10.1016/j. eururo.2016.02.029

25. Lee S, Park YH, Chung JS, Yoo YD (2015) Romo1 and the NF$\mathrm{\kappa B}$ pathway are involved in oxidative stress-induced tumor cell invasion. Int J Oncol 46(5):2021-2028. https://doi.org/10.3892/ ijo.2015.2889

26. Bohovych I, Dietz JV, Swenson S, Zahayko N, Khalimonchuk O (2019) Redox regulation of the mitochondrial quality control protease Oma1. Antioxid Redox Signal. https://doi.org/10.1089/ ars.2018.7642

27. Amini MA, Karimi J, Khodadadi I, Tavilani H, Talebi SS, Afshar B (2019) Overexpression of ROMO1 and OMA1 are potentially biomarkers and predict unfavorable prognosis in gastric cancer. J Gastrointest Cancer. https://doi.org/10.1007/s12029-019-00330-w

28. Jo MJ, Jeong S, Yun HK, Kim DY, Kim BR, Kim JL, Na YJ, Park SH, Jeong YA, Kim BG (2019) Genipin induces mitochondrial dysfunction and apoptosis via downregulation of Stat $3 / \mathrm{mcl}-1$ pathway in gastric cancer. BMC Cancer 19(1):739. https://doi. org/10.1186/s12885-019-5957-x

29. Costa D, Scognamiglio M, Fiorito C, Benincasa G, Napoli C (2019) Genetic background, epigenetic factors and dietary interventions which influence human longevity. Biogerontology. https ://doi.org/10.1007/s10522-019-09824-3

30. Lee SH, Choi SI, Lee JS et al (2018) Overexpression of reactive oxygen species modulator 1 is significantly associated with advanced stage and poor survival in non-small cell lung cancer. Cancer Res Treat 49(1):141-149. https://doi.org/10.4143/ crt.2016.133

31. Chung YM, Kim JS, Do Yoo Y (2006) A novel protein, Romo1, induces ROS production in the mitochondria. Biochem Biophys Res Commun 347(3):649-655. https://doi.org/10.1016/j. bbrc.2006.06.140

32. Shin JA, Chung JS, Cho S-H, Kim HJ, Do Yoo Y (2013) Romo1 expression contributes to oxidative stress-induced death of lung epithelial cells. Biochem Biophys Res Commun 439(2):315-320. https://doi.org/10.1016/j.bbrc.2013.07.012

33. Liu D, Liu Y, Xia Z, Dong H, Yi Z (2017) Reactive oxygen species modulator 1 regulates oxidative stress and induces renal and 
pulmonary fibrosis in a unilateral ureteral obstruction rat model and in HK-2 cells. Mol Med Rep 16(4):4855-4862. https://doi. org/10.3892/mmr.2017.7161

34. Kim IG, Kim SY, Kim HA, Kim JY, Lee JH, Im Choi S, Han JR, Kim KC, Cho EW (2014) Disturbance of DKK1 level is partly involved in survival of lung cancer cells via regulation of ROMO1 and $\gamma$-radiation sensitivity. Biochem Biophys Res Commun 443(1):49-55. https://doi.org/10.1016/j.bbrc.2013.11.038

35. Lee JS, Chang JS, Lee JY, Kim JA (2004) Capsaicin-induced apoptosis and reduced release of reactive oxygen species in MBT-2 murine bladder tumor cells. Arch Pharm Res 27(11):1147-1153. https://doi.org/10.1007/bf02975121

36. Desouky E (2020) BCG versus COVID-19: impact on urology. World J Urol. https://doi.org/10.1007/s00345-020-03251-7

37. Richter F, Dennerlein S, Nikolov M, Jans DC, Naumenko N, Aich A, MacVicar T, Linden A, Jakobs S, Urlaub H (2019) ROMO1 is a constituent of the human presequence translocase required for YME1L protease import. J Cell Biol 218(2):598-614. https://doi. org/10.1083/jcb.201806093
38. Setyawan EMN, Kim MJ, Oh HJ, Kim GA, Jo YK, Lee SH, Choi YB, Lee BC (2016) Spermine reduces reactive oxygen species levels and decreases cryocapacitation in canine sperm cryopreservation. Biochem Biophys Res Commun 479(4):927-932. https:// doi.org/10.1016/j.bbrc.2016.08.091

39. Ranjbaran J, Farimani M, Tavilani H, Ghorbani M, Karimi J, Poormonsefi F, Khodadadi I (2016) Matrix metalloproteinases 2 and 9 and MMP9/NGAL complex activity in women with PCOS. Reproduction 151(4):305-311. https://doi.org/10.1530/ REP-15-0340

Publisher's Note Springer Nature remains neutral with regard to jurisdictional claims in published maps and institutional affiliations. 